\title{
Methodological Approach in Perception Management
}

\author{
Mehmet Tuğrul Cabığlu1, Sevgin Özlem İşeri² \\ ${ }^{1}$ Department of Physiology, Başkent University Faculty of Medicine, Ankara, Turkey \\ ${ }^{2}$ Department of Medical Biochemistry, Hacettepe University Faculty of Medicine, Ankara, Turkey \\ Email: tugcab@gmail.com, sevginiseri@gmail.com
}

Received 8 July 2015; accepted 25 July 2015; published 31 July 2015

Copyright (C) 2015 by authors and OALib.

This work is licensed under the Creative Commons Attribution International License (CC BY).

http://creativecommons.org/licenses/by/4.0/

(c) (i) Open Access

\begin{abstract}
Perception is the interpretation of the sensory stimuli received from the environment. Visual, auditory, and tactile senses are collected and interpreted in the "General Interpretation Area" (Wernicke's area). This area alone plays a much more active role than all other regions of the cortex in the comprehension of the brain called intelligence. We comprehend the events as a whole with the combination of the visual, auditory, and tactile perceptions in the Wernicke's area; the events remain longer in our memory and its impact on us is stronger. This situation is called multi-sensory perception. Different pressure groups are in an effort to influence the feelings, sensations, systems of thought, and actions of their target population in order to ensure their target population to behave in line with their targets. In this respect, "Perception Management" is defined as all activities that are performed to influence the thoughts of a target population. Modeling, focusing attention on a specific point, creating an expectation, participation, rewarding, punishment, and stress management are among the methods applied in perception management. If we learn these methodological approaches used in perception management, we are in the opinion that it would be easy for individuals to decide independently by preventing them from the influence and manipulation of different pressure groups on their decision-making processes. Today, pressure groups aim at managing the community in line with their targets by influencing single individuals mostly using the perception management method.
\end{abstract}

\section{Keywords}

Perception, Perception Management, Dopamine, Cortisol, Oxytocin

Subject Areas: Neuroscience

\section{Introduction}

Today, advances in technology allow people to access information quite rapidly and easily. As a result, there has 
been an increase in the number of ways of accessing and obtaining information. Individuals are exposed to an information overload from electronic media such as television, internet, radio, and movies [1]. The sense organs receive stimuli of $10^{9} \mathrm{bit} / \mathrm{second}$ from the environment. However, a very small portion of these stimuli, as small as $100-1000 \mathrm{bit} / \mathrm{second}$, is consciously recorded by the cerebral cortex; whereas, the remaining portion is either subconsciously processed or almost not used. The unit of stimulus content is digit or bit. Stimulus flow is a timedependent process (bit/second). A letter is 4.5 bit and a book page is 1000 bit [2].

Stimuli received by the sense organs enable recognition of the environment. Information obtained from the external world is processed in two different levels. The first level is sensation and the second level is perception. In order to better understand the concept of "Perception Management", the meanings of the terms "sensation" and "perception" should be emphasized.

\section{Definitions of Perception and Perception Management}

Sensation stands for receiving sensory stimulus. Sensation is considered as the impression obtained by an individual via senses. Sensation, for example, is the brightness of the light seen, feeling warmth while holding a cup of hot tea, and the pain felt when a pin is pricked into any part of the body. Perception is the organization and interpretation of the sensory stimuli received and is the process of making sense of the stimuli in the environment [3]. For instance, senses of brightness and warmth felt over the body of an individual are interpreted as sunlight and senses of coldness and wetness are interpreted as rain. This is the state of being in a conscious effort to understand the sensorial data transported via sense organs by organizing and interpreting them. Perception is defined as comprehending and apprehending something by directing the attention. A number of pre-existing templates are required for perception. These templates can be established by an inductive information processing. During this inductive information processing, stimuli that are classified as those simultaneously sensed, those with similarities, and those with differences, etc. Afterwards, "prototypes" occur and templates or schemas are established.

Perception management includes all studies conducted by the pressure groups to influence emotions, sensations, system of thoughts, and behaviors of the target population by directing collection, organization, and interpretation of information or manipulating or disapproving flow of selected information or solid documents in order to enable the target population to act in the direction of their targets. With this definition, "Perception Management" covers all activities performed to influence the thoughts of target population. Different pressure groups can manipulate our perceptions as if their own targets and benefits are consistent with our benefits.

"Perception Management" is one of the methods of persuasion. It is the sum of all essential techniques used to persuade someone for purchasing a product, a service or an idea. If reception, organization and interpretation of sensory stimuli are performed by ourselves or by a team that we are in or trust, this means that we create our own perceptions. However, perceptions can be managed by pressure groups by interfering in one or more of the reception, organization, and interpretation steps of sensorial stimuli.

The $21^{\text {st }}$ century is referred to as the century of information technologies. In this century, the methods of warfare have changed. Armed combat techniques have been replaced by perception management, in which weapons are not involved; it has become easier to influence the people of target population with the help of easy accessibility of the mass communication technologies by individuals.

While pressure groups are manipulating communities in line with their targets, they can exaggerate the small dissents (ethnic, religious or formal) in a community and can even drag community into a conflict by perception management method. On the contrary, they can cause communities to ignore the existing dissents and problems by this method.

Technological developments enable people to obtain information particularly in the electronic media. Therefore, perception management is one of the key factors to be successful in the discussions that are ongoing in the field of information warfare [4].

\section{Physiology of Perception}

In order to understand the concept of "Perception Management”, it is necessary to know how people perceive, i.e. the physiology of perception.

The majority of people in the population learns from graphics and figures by seeing and reading [5] [6]. Visual pathways and areas occupy a large space in the brain and thereby visual exposure is important. Visual senses 
are collected in the primary visual area of the occipital lobe of the brain, and then they are sent to the secondary visual area found just above the primary visual area and are processed, i.e. visual perception occurs (Figure 1) [7].

People with stronger auditory perception learn better by listening [5]. These individuals easily remember the substantial proportion (approximately 75\%) of what they hear and discuss. Nevertheless, auditory perception is more predominant in less than $30 \%$ of school-age children [8]. Auditory senses are collected in the primary auditory area of the temporal lobe of the brain and they are then sent to the secondary auditory area found just anterior to the primary auditory area. They are processed and interpreted in the secondary auditory area and auditory perception occurs (Figure 1) [7].

People with stronger tactile perception learn best by touching [6]. They try to tell their emotions and feelings by touching. Therefore, they should be appreciated by physical contact rather than verbal reinforcers. Taking notes or writing the taught subjects may help them in remembering information [5]. Tactile sensations are collected in the somatic area in the parietal lobe of the brain. Tactile sensations are processed and interpreted in the somatic area, i.e., tactile perception occurs (Figure 1) [7].

All auditory, tactile and visual perceptions are collected in an area called General Interpretation Area (Wernicke's Area) and they are interpreted all together in this area (Figure 1). This area alone plays a much more active role than all other regions of the cortex in the comprehension of the ultimate functions of the brain called intelligence [7].

We comprehend the events as a whole with the combination of the visual, auditory, tactile, taste, and smell perceptions in the "General Interpretation Area” (Wernicke’s Area) (Figure 1). While mentioning an event, if we activate the senses of vision, hearing, touching, smelling and taste all at once, they remain longer in our memory and have a strong impact on us. This is called multi-sensory perception.

According to the previous studies, in case of exposure to negative news via media, the stress response in females has been observed to increase more than normal not while watching the news but during a subsequent exposure to a similar negative event. Additionally, memory for negative events and also stress response have been shown to be increased via media [9].

\section{Methods Used in Perception Management}

Modeling, focusing attention on a specific point, participation, rewarding, punishment, and stress management are just some of the methods used in the perception management (Table 1). In this review, we will examine only the methods just mentioned above.

\subsection{Modeling}

Individuals may model each other by means of "mirror neurons". Mirror neurons were discovered in 1990s; Vittorio Gallese and his team from Parma University, Italy were the first to demonstrate a different motor neuron called "mirror neuron" in the premotor region (F5) of macaque monkeys and conducted studies on this issue

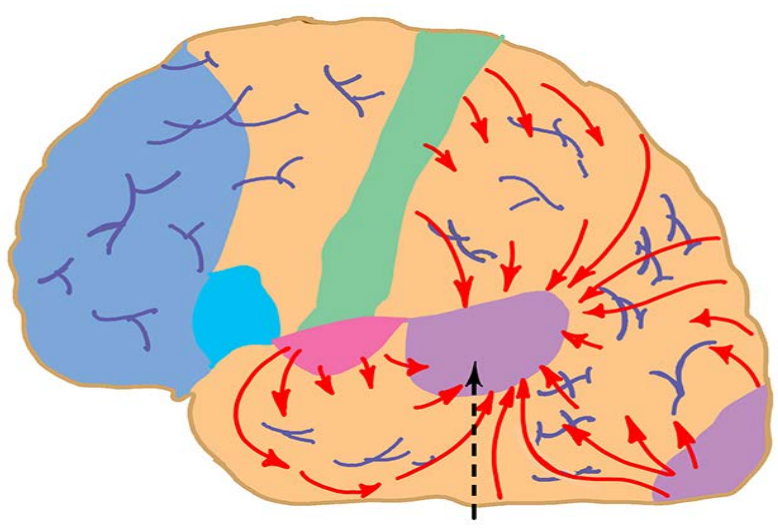

Figure 1. General interpretation area (Wernicke's area) where all visual, auditory, and tactile perceptions are collected. 
Table 1. Methods used in perception management.

\begin{tabular}{cr}
\hline Methods & Description \\
\hline Modeling & Imitating with the activation of mirror neurons \\
Focusing Attention on a Specific Point & Focusing attention on a specific point \\
Participation & Ensuring the participation of individuals \\
Rewarding & Motivating by rewarding \\
Punishment & The dominance of punishment over rewarding \\
Stress Management & A certain level of stress creating insensibility after a certain period of \\
time
\end{tabular}

[10].

Mirror neurons are the brain cells stimulated not only during motor activation but also during observation of motor movements [11]. It is believed that mirror neuron system in human is the basic mechanism necessary for social cognition. Moreover, it is also believed that mirror neurons are necessary for functions such as understanding the process, intention, and emotion in any activity [12] [13]. Mirror neurons allow us to imitate the movements, facial mimics [14] [15], and emotions [16] of other people. Mirror neurons have been shown to be activated more along with increased social activity, i.e., increased involvement of individuals in social activities [17]. Empathy, which is defined as establishing an immediate and automatic connection with emotional state of another, is necessary for social communication [18]. Empathy is also the way of thinking and feeling like other individuals temporarily [19] and allows us to understand other individuals emotionally [20]. Mirror neurons play a role in empathizing; with the discovery of mirror neurons, it has become evident that the brain, which was formerly thought to work individually and totally independent, is in interaction with the individuals around as if they are connected by a network. We are surrounded by the people from "our world", not by the people from "the world different than ours" and us. Therefore, the more a community leader empathizes with various sections of the population, the more his/her emotions and thoughts are understood and imitated by other people; in brief, the more effective he/she becomes on the population. Community leaders present themselves as a model by activating mirror neurons of individuals. A community leader wants to manage the perception of individuals by activating their mirror neurons and thereby leading the individuals to imitate his/her movements, emotions, senses, and mimics. Moreover, it is possible to get individuals involved in a social activity and make them much more influenced by this activity.

\subsection{Focusing Attention on a Specific Point, Creating an Expectation}

Chabris and Simons [21] divided their students into two groups dressing them either white or black shirts, asked them to pass basketballs to each other, and filmed them for less than 1 minute. In the middle of the video, a girl wearing a gorilla costume spent 9 seconds on the screen. The subjects who watched the video were asked to keep a silent count of the number of passes made by the players in white shirts and answer the question "While you were doing the counting, did you notice anything unusual on the video?”. However, half of the subjects could not see the girl in gorilla costume appeared on the screen for 9 seconds. This illusion of perception was due to not paying attention to an unexpected object. This can be called as "inattentional blindness".

Oxytocin is a crucial neuropeptide for learning, memory, and organization of behaviors in the mammalians [22]. Central oxytocin receptors are widely found in the brain in the hippocampus, amygdala, striatum, hypothalamus, nucleus accumbens, and midbrain and play an important role in the formation of memory [23]. It has been explained that dopaminergic neurons in the hippocampus and its environment as well as their extensions in the nucleus accumbens are activated with being in an expectation and this facilitates learning by playing a regulatory role in the formation of memory in the medial temporal lobe. Oxytocin is important in positive social interaction, inhibits stress response, and regulates cognitive performance (such as learning and memory) [24]. Painful experience during delivery is forgotten because of short-term amnestic effect of central oxytocin; in addition, oxytocin also enables mothers to be isolated from distracting stimuli in the environment during lactation and to fully focus on her baby [25] [26].

Being in an expectation increases dopamine secretion from the nucleus accumbens found in the cerebral cor- 
tex. Morphine also increases dopamine secretion from the nucleus accumbens, i.e., morphine and being in an expectation create the same effect on the brain. Dopamine release decreases, when an expectation ends. Increasing effect of morphine on dopamine release from the nucleus accumbens is suppressed by Gly-Gln, which is one of the degradation products of $\beta$-endorphin, and thus rewarding effect of morphine is eliminated [27] [28].

People who intend to manage the perceptions get the population to come along by deliberately shifting the population from one expectation to another. They also take the public away from a topic that is unwanted to be recognized by making them focus on another specific topic.

\subsection{Participation}

Oberman et al. [17] made 20 university students watch 4 different videos. They examined mirror neuron activities by electroencephalography while the subjects were watching the videos. Of the videos, the 1st video was a blank, white screen as the control video; the 2nd video showed three subjects tossed a ball up in the air to themselves, indicating the absence of social activity; the 3rd video showed three subjects tossed a ball to each other, indicating the presence of social activity; and the 4th video showed the same thing in the 3rd video except occasionally the ball would be thrown off the screen, seemingly toward the subject, indicating the presence of social activity and the interaction of the subject. Based on the recordings of that particular study, an increase was determined in mirror neuron activity as the participation of the subjects in social activity increased. It was concluded that if an individual's high level of participation in decision-making was enabled, the mirror neurons would be activated and thus his/her perception would be influenced favorably [17].

In a previous study, being in a social environment has been shown to increase oxytocin level [29]. It has been observed that wound healing is delayed with social isolation and that healing is also delayed in burn-induced ileal stress injury in the event of social isolation [29]. Social cognitive skills such as empathy, emotional perception, and developing a reasonable perspective are impaired in schizophrenic patients and this condition has been found to arise from a dysfunction in the oxytocinergic system and likely to be improved with oxytocin therapy [30].

\subsection{Rewarding}

Rewarding is methodologically used in influencing the perception of an individual. In addition to its psychological effect, rewarding also has physiological effects on an individual. Rewarding an individual leads to an activation in the lateral and ventromedial nuclei of the hypothalamus and in the medial forebrain bundle. While weak stimuli of the lateral nuclei of the hypothalamus generates a feeling of rewarding, strong stimuli generates a feeling of punishment [7].

\subsection{Punishment}

Punishment also is used methodologically in influencing the perception of an individual. In addition to its psychological effects, punishment also has physiological effects on an individual. The strongest punishment and avoidance feelings stimulate the central gray matter that surrounds the Sylvius aqueduct in the mesencephalon. It has been emphasized that punishment and fear prevail pleasure and reward [7].

\subsection{Stress Management}

The influence of the media on population has substantially increased in the last decade due to 24-hour broadcasting television channels, internet, and smartphones. Studies have observed a gradual decrease in the cortisol response to stress, an enhancement in tolerance, and unresponsiveness in the subjects who are accustomed to hearing stressful news continuously via the media.

Researchers have demonstrated that lower levels of cortisol, which is a stress hormone secreted from the hypothalamic-pituitary-adrenal axis, are required for achieving higher social levels [31]. Response to stress by the hypothalamic-pituitary-adrenal axis is regulated by an increase in plasma oxytocin level induced by cortisol and thereby the probability of easy remembering of the undesirable situation in the future is selectively decreased. Accordingly, it has been demonstrated that increased cortisol level and thereby increased oxytocin level at a stressful situation have a substantial role on the improvement of social behavior during a stressful event [32].

The relation between leadership and stress has been investigated and an inverse relation has been demon- 
strated between stress and leadership. In other words, it has been demonstrated that the leaders who are stronger and take higher responsibilities have significantly lower cortisol levels at the time of stress as compared to other individuals [33]. The response of individuals to stress is crucial in perception management.

Pressure groups are in an effort to influence the feelings, sensations, systems of thought, and actions of their target population in order to ensure their target population to behave in line with their targets. These pressure groups want us to perceive their own targets and benefits as if they are our own targets and benefits.

\section{Conclusion}

In conclusion, modeling, focusing attention on a specific point, creating an expectation, participation, rewarding, punishment, and stress management are among the methods used in perception management. Nowadays, different pressure groups are frequently in an effort to manipulate the population in line with their targets by performing perception management methods in the individuals and in the population through the individuals. We are in the opinion that if we learn these methodological approaches used in perception management, we are in the opinion that it would be easy for individuals to decide independently by preventing them from the influence and manipulation of different pressure groups on their decision-making processes.

\section{References}

[1] Stupak, R.J. (2000) Perception Management: An Active Strategy for Marketing and Delivering Academic Excellence, Business Sophistication, and Communication Successes. Public Administration and Management, 5, 250-260.

[2] Despopoulos, A. and Silbernagl, S. (2008) Color Atlas of Physiology. 6th Edition, Thieme, Stuttgart New York.

[3] Arkonaç, S.A. (1998) Psikoloji: Zihin Süreçleri Bilimi. 2nd Edition, Alfa Yayınları, İstanbul.

[4] Friman, H. (1999) Perception Warfare: A Perspective for the Future. http://citeseerx.ist.psu.edu/viewdoc/download?doi=10.1.1.189.4565\&rep=rep1\&type=pdf

[5] Dunn, R. (1988) Commentary: Teaching Students through Their Perceptual Strengths or Preferences. Journal of Reading, 31, 304-309.

[6] Reid, J.M. (1998) Understanding Learning Styles in the Second Language Classroom. Prentice Hall Regents, Upper Saddle River.

[7] Guyton, A.C. and Hall, J.E. (2006) Textbook of Medical Physiology. Saunders Elsevier, Philadelphia.

[8] Dunn, R. and Milgram, R.M. (1993) Learning Styles of Gifted Students in Diverse Cultures. In: Milgram, R.M., Dunn, R. and Price, G.E., Eds., Teaching and Counseling Gifted and Talented Adolescents: An International Learning Style Perspective, Westport, Praeger, 3-23.

[9] Marin, M.F., Morin-Major, J.K., Schramek, T.E., Beaupré, A., Perna, A., et al. (2012) There Is No News Like Bad News: Women Are More Remembering and Stress Reactive after Reading Real Negative News Than Men. PLoS One, 7, e47189. http://dx.doi.org/10.1371/journal.pone.0047189

[10] Gallese, V., Fadiga, L., Fogassi, L. and Rizzolatti, G. (1996) Action Recognition in the Premotor Cortex. Brain, 119, 593-609. http://dx.doi.org/10.1093/brain/119.2.593

[11] Puzzo, I., Cooper, N.R., Vetter, P. and Russo, R. (2010) EEG Activation Differences in the Pre-Motor Cortex and Supplementary Motor Area between Normal Individuals with High and Low Traits of Autism. Brain Research, 1342, 104110. http://dx.doi.org/10.1371/journal.pone.0047189

[12] Rizzolatti, G., Fadiga, L., Gallese, V. and Fogassi, L. (1996) Premotor Cortex and the Recognition of Motor Actions. Cognitive Brain Research, 3, 131-141. http://dx.doi.org/10.1093/brain/119.2.593

[13] Rizzolatti, G., Fogassi, L. and Gallese, V. (2006) Mirrors of the Mind. Scientific American, 295, 54-61. http://dx.doi.org/10.1038/scientificamerican1106-54

[14] Ferrari, P.F., Gallese, V., Rizzolatti, G. and Fogassi, L. (2003) Mirror Neurons Responding to the Observation of Ingestive and Communicative Mouth Actions in the Monkey Ventral Premotor Cortex. European Journal of Neuroscience, 17, 1703-1714. http://dx.doi.org/10.1046/j.1460-9568.2003.02601.x

[15] Joly-Mascheroni, R.M., Senju, A. and Shepherd, A.J. (2008) Dogs Catch Human Yawns. Biology Letters, 4, $446-448$. http://dx.doi.org/10.1098/rsbl.2008.0333

[16] Lorberbaum, J.P., Newman, J.D., Dubno, J.R., Horwitz, A.R., Nahas, Z., et al. (1999) Feasibility of Using fMRI to Study Mothers Responding to Infant Cries. Depression and Anxiety, 10, 99-104. http://dx.doi.org/10.1002/(SICI)1520-6394(1999)10:3<99::AID-DA2>3.0.CO;2-\#

[17] Oberman, L.M., Pineda, J.A. and Ramachandran, V.S. (2007) The Human Mirror Neuron System: A Link between Ac- 
tion Observation and Social Skills. Social Cognitive and Affective Neuroscience, 2, 62-66. http://dx.doi.org/10.1093/scan/nsl022

[18] De Waal, F.B.M. and Thompson, E. (2005) Primates, Monk and the Mind. Journal of Consciousness Studies, 12, 1-17.

[19] Batson, C.D., Kobrynowicz, D., Dinnerstein, J.L., Kampf, H.C. and Wilson, A.D. (1997) In a Very Different Voice: Unmasking Moral Hypocrisy. Journal of Personality and Social Psychology, 72, 1335-1348. http://dx.doi.org/10.1037/0022-3514.72.6.1335

[20] Starcevic, V. and Piontek, C.M. (1997) Empathic Understanding Revisited: Conceptualization, Controversies, and Limitations. American Journal of Psychotherapy, 51, 317-328.

[21] Chabris, C. and Simons, D. (2010) The Invisible Gorilla: and Other Ways Our Intuitions Deceive Us. Crown, New York.

[22] MacDonald, K. and MacDonald, T.M. (2010) The Peptide That Binds: ASystematic Review of Oxytocin and Its Prosocial Effects in Humans. Harvard Review of Psychiatry, 18, 1-21. http://dx.doi.org/10.3109/10673220903523615

[23] Gimpl, G. and Fahrenholz, F. (2001) The Oxytocin Receptor System: Structure, Function, and Regulation. Physiological Reviews, 81, 629-683.

[24] Carter, C.S. (1998) Neuroendocrine Perspectives on Social Attachment and Love. Psychoneuroendocrinology, 23, 779818. http://dx.doi.org/10.1016/S0306-4530(98)00055-9

[25] Heinrichs, M., Meinlschmidt, G., Wippich, W., Ehlert, U. and Hellhammer, D.H. (2004) Selective Amnesic Effects of Oxytocin on Human Memory. Physiology \& Behavior, 83, 31-38. http://dx.doi.org/10.1016/s0031-9384(04)00346-4

[26] Heinrichs, M., Neumann, I. and Ehlert, U. (2002) Lactation and Stress: Protective Effects of Breast-Feeding in Humans. Stress, 5, 195-203. http://dx.doi.org/10.1080/1025389021000010530

[27] Basaran, N.F., Buyukuysal, R.L., Millington, W.R. and Cavun, S. (2010) Glycyl-Glutamine (Beta-Endorphin(30-31)) Inhibits Morphine-Induced Dopamine Efflux in the Nucleus Accumbens. Naunyn-Schmiedeberg's Archives of Pharmacology, 381, 467-475. http://dx.doi.org/10.1007/s00210-010-0507-8

[28] Parish, D.C., Smyth, D.G., Normanton, J.R. and Wolstencroft, J.H. (1983) Glycyl Glutamine, an Inhibitory Neuropeptide Derived from Beta-Endorphin. Nature, 306, 267-270. http://dx.doi.org/10.1038/306267a0

[29] Işeri, S.O., Düşünceli, F., Erzik, C., Uslu, B., Arbak, S., et al. (2010) Oxytocin or Social Housing Alleviates Local Burn Injury in Rats. Journal of Surgical Research, 162, 122-131. http://dx.doi.org/10.1016/j.jss.2009.02.018

[30] Fischer-Shofty, M., Brüne, M., Ebert, A., Shefet, D., Levkovitz, Y., et al. (2013) Improving Social Perception in Schizophrenia: The Role of Oxytocin. Schizophrenia Research, 146, 357-362. http://dx.doi.org/10.1016/j.schres.2013.01.006

[31] Sapolsky, R.M. (1989) Hypercortisolism among Socially Subordinate Wild Baboons Originates at the CNS Level. JAMA (Archives of General Psychiatry), 46, 1047-1051. http://dx.doi.org/10.1001/archpsyc.1989.01810110089012

[32] Tops, M., Buisman-Pijlman, F.T., Boksem, M.A., Wijers, A.A. and Korf, J. (2012) Cortisol-Induced Increases of Plasma Oxytocin Levels Predict Decreased Immediate Free Recall of Unpleasant Words. Frontiers in Psychiatry, 3, 43. http://dx.doi.org/10.3389/fpsyt.2012.00043

[33] Sherman, G.D., Lee, J.J., Cuddy, A.J., Renshon, J., Oveis, C., et al. (2012) Leadership Is Associated with Lower Levels of Stress. Proceedings of the National Academy of Sciences of the United States of America, 109, 17903-17907. http://dx.doi.org/10.1073/pnas.1207042109 